\title{
EVALUACIÓN DE LA PRESENCIA DE BACTERIAS GRAM NEGATIVAS FERMENTADORAS DE CARBOHIDRATOS EN SÁNDWICH QUE SE COMERCIALIZAN EN LA UNIVERSIDAD RICARDO PALMA
}

\author{
José Cerapio \\ $K$ Sanchez, \\ $R$ Via y Rada \\ Juan Carlos Ramos \\ Tomas Agurto
}

\begin{abstract}
RESUMEN
Como es sabido, la mayor causa de enfermedades trasmitidas por los alimentos se debe al consumo de éstos fuera del hogar, como lo son, comedores públicos, restaurantes, tiendas, etc. Es por este motivo que se requiere un efectivo control sanitario, lo cual es posible gracias a las técnicas de análisis microbiológicas que nos permiten la detección de organismos patógenos. Se realizó un análisis microbiológico de sándwich-triples de puestos de diferentes facultades de la Universidad Ricardo Palma, determinando la presencia de bacterias Gram negativas fermentadoras de citrato del género Citrobacter.
\end{abstract}

Palabras clave: Citrobacter, Citrobacter, Gram negativas, patógeno, contaminación cruzada, intoxicación.

\begin{abstract}
As is known, the major cause of diseases transmitted by food is due to the use of these products outside the home, such as, public dinnig, restaurants, café's, stores, etc. It's for this reason that effective control is required, which is made possible by microbiological analysis techniques that allow the detection of pathogenic organisms. Microbiological analysis was performed in sandwich-triple of the different food stores of the Ricardo Palma University, determining the presence of gram negative bacteria fermenting of citrate belongs to Citrobacter family.
\end{abstract}

Key words: Citrobacter, Gram negatives, pathogen contamination, intoxication.

\section{INTRODUCCIÓN}

Uno de los factores que en mayor medida afectan a la Salud Pública es la falta de higiene de los alimentos, especialmente en comedores públicos donde se atienen diariamente a numerosas personas, siendo el análisis microbiológico una herramienta eficaz en la evaluación de un alimento, con la finalidad de determinar su calidad e inocuidad.

Cualquier alimento debería estar, en condiciones ideales, libre de microorganismos patógenos y en un reducido numero de los no patógenos como indica la Norma Sanitaria. Sin embargo, debido a la informalidad de los puestos de comida parece ser imposible que se tenga especial cuidado con el manejo de los alimentos.

Una correcta higiene de los alimentos está determinada por multitud de factores como: condiciones de obtención de la materia prima para la fabricación del alimento, características de los medios empleados para su transporte, temperaturas y condiciones de conservación, infraestructura de los locales donde se manipulan los alimentos, etc., destacando entre todos ellos la higiene personal de los manipuladores de alimentos (Pérez- Silva García, 1998). Todos estos factores mencionados, se encuentran involucrados en el manejo de los alimentos y son determinantes para su calidad e inocuidad.

Como es sabido, la mayor causa de enfermedades trasmitidas por los alimentos se debe al consumo de éstos fuera del hogar, como lo son comedores públicos o colectivos. Entre los comedores colectivos, se encuentran por ejemplo, los Kioskos de productos envasados y comida dentro de las universidades, como es el caso de la Universidad Ricardo Palma que encontramos numerosos kioskos de productos envasados y comida que cuentan con autorización

\footnotetext{
Laboratorio de Microbiología y Parasitología de la Facultad de Ciencias Biológicas de la Universidad Ricardo Palma. Av. Benavides 5440, Lima 33, Perú. Email: juanramosgo@yahoo.es
} 
sanitaria. Sin embargo, estos documentos no certifican que la venta de productos envasados y preparados sean de calidad e inocuos para la salud, sin que exista un programa de vigilancia sanitaria que los supervisen.

El objetivo de nuestra investigación es evaluar la calidad e inocuidad de sándwich triples que se venden en los kioskos que se ubican en la Universidad Ricardo Palma determinando la presencia de bacterias Gram negativas fermentadoras de carbohidratos.

\section{MATERIALES Y MÉTODOS}

Se realizaron en dos ensayos durante el mes de Mayo, 2011. Analizándose con un total de 5 triples por cada ensayo, teniendo una etapa de preenriquecimiento, posteriormente se cultivaron en medios de cultivos selectivos para la obtención del cepario y finalmente se realizó las pruebas bioquímicas de identificación.

\section{Material biológico y puntos de muestreo}

Para la obtención de material biológico, se procedió a comprar sándwich triples que podían variar en sus ingredientes siempre y cuando tenga huevo cocido, de kioskos ubicados en la Facultad de Ingeniería, Facultad de Arquitectura, Facultades de Ciencias Económicas y Empresariales, Psicología y Ciencias Biológicas de la Universidad Ricardo Palma, las cuales se codificaron para facilitar la realización del trabajo; A, B, C, D y E respectivamente. (Figura 1)

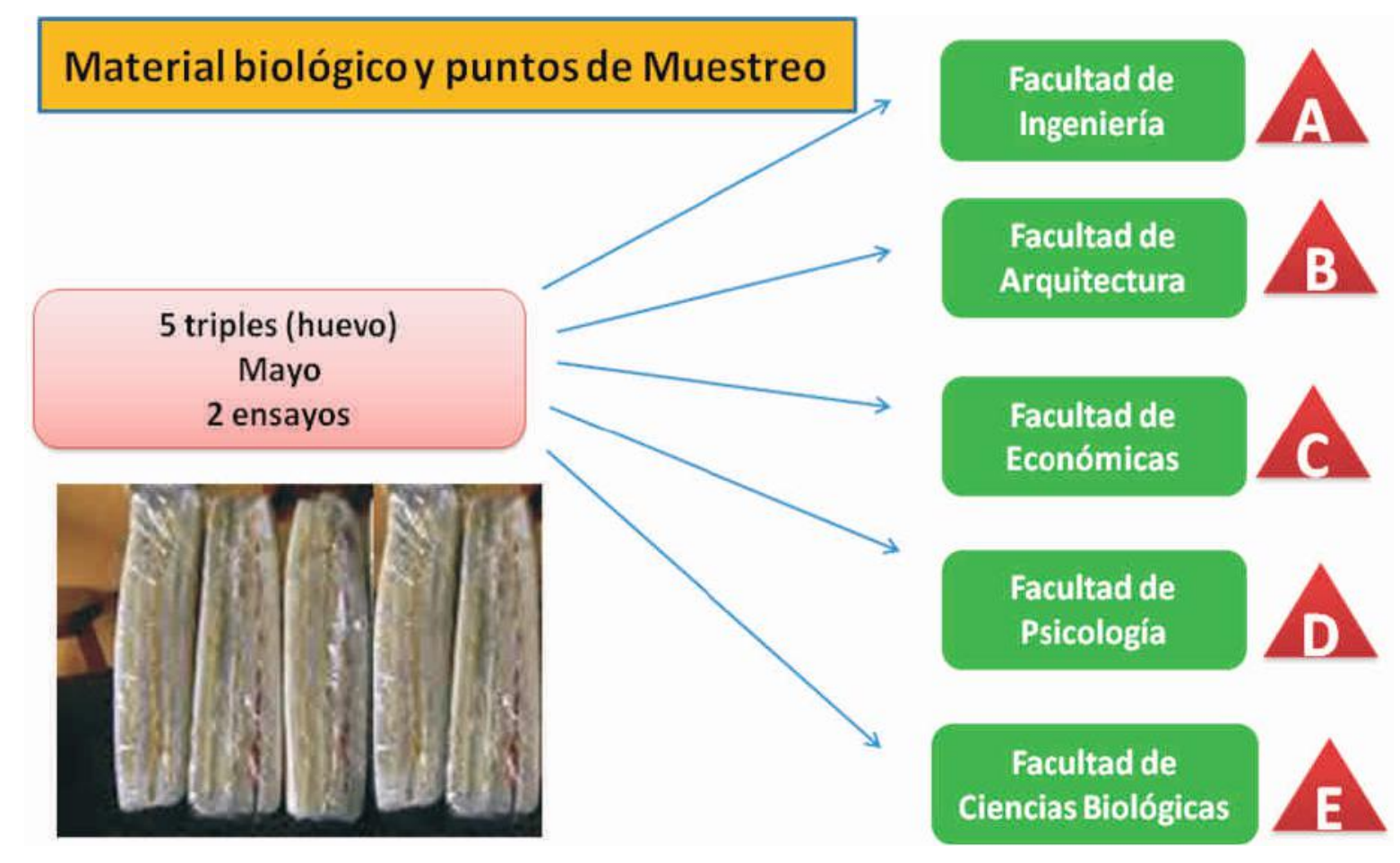

Fig. 1. Material biológico y puntos de Muestreo

\section{Preparación de medios y Pruebas Bioquímicas}

Como se mencionó al principio se realizaron 2 ensayos. Se preparó caldo de enriquecimiento Tetrationato para Salmonella, 1 frasco para cada muestra ya que la solución sobrenadante es la que se usó para la siembra. Para ambos ensayos se prepararon 2 repeticiones de placas con medio de cultivo Selectivo Agar Salmonella - Shigella para cada muestra. Luego se prepararon ceparios con agar nutritivo para aislar las bacterias que desarrollaran en los medios selectivos e identificarlas posteriormente. Finalmente se prepararon los medios de cultivo para las pruebas bioquímicas consistiendo básicamente en Agar Tres Azucares Hierro (TSI), Agar Lisina Hierro (LIA), Medio SIM y Agar Citrato de Simons. (Figura 2)

La prueba en el Medio SIM, es un medio semisólido para evaluar la motilidad de la bacteria, el TSI se preparó para evaluar el metabolismo de lactosa, sacarosa y glucosa. El medio LIA, para a evalar la capacidad de la bacteria de metabolizar la lisina y Agar Citrato de Simmons para detectar la capacidad asimilar el citrato. 


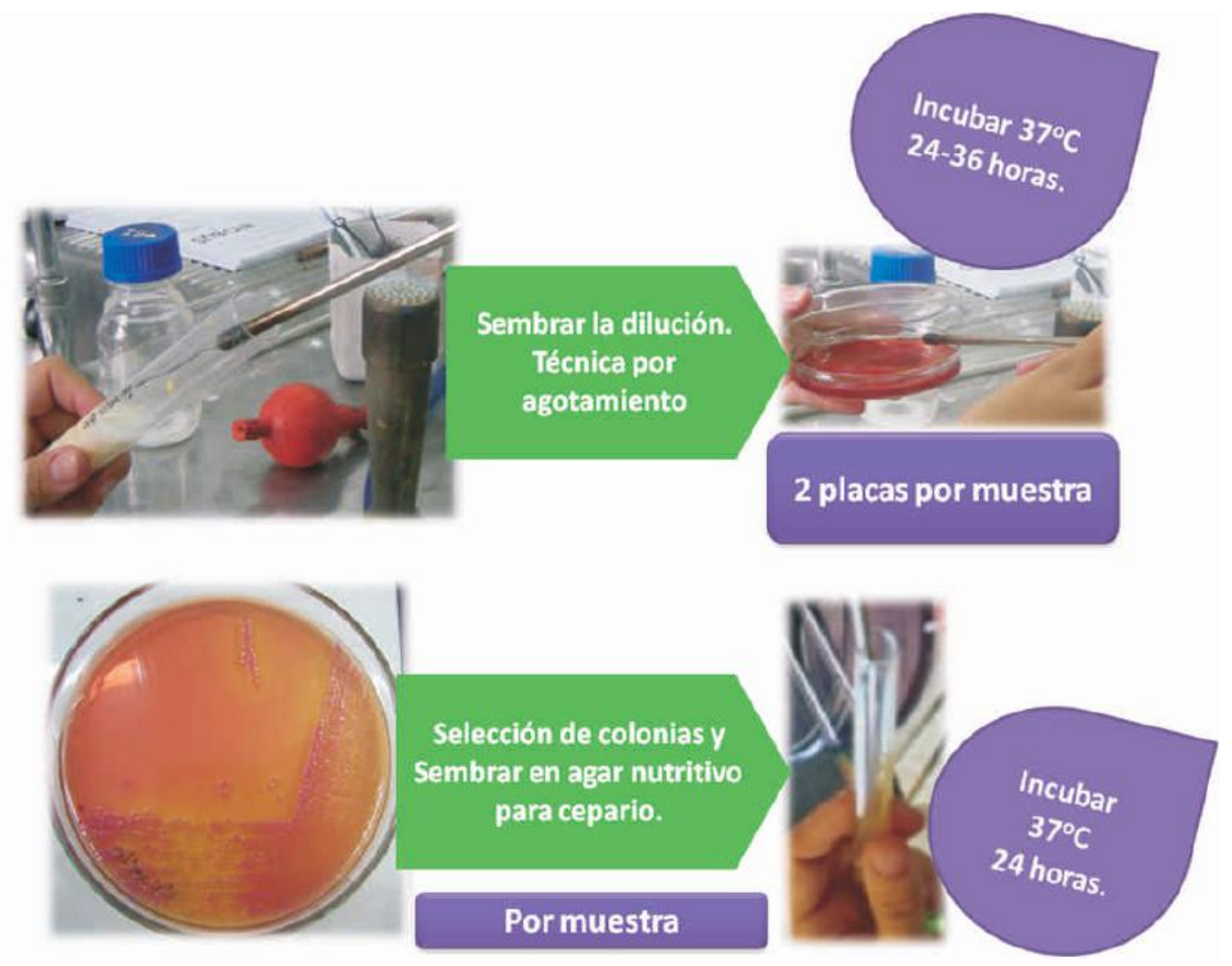

Fig. 2. Procedimiento de siembra

\section{Realización de la siembra y de las pruebas bioquímicas}

Una vez obtenidos los sándwich triples de los puntos mencionados, se transportaron con mucho cuidado al Laboratorio de Microbiología para su análisis respectivo.

De cada triple se procedió a cortar $10 \mathrm{~g}$ de muestra para luego introducirlos en frascos con $50 \mathrm{~mL}$ Caldo Tetrationato cada uno, se homogenizó bien y se dejó reposar durante 24 horas a $37^{\circ} \mathrm{C}$ para permitir la viabilización de las células bacterianas gramnegativas presentes.

Secuelas del cultivo fueron sembrados con ayuda de un asa de siembra de $3 \mathrm{~mm}$ de diámetro usando la técnica por agotamiento por duplicado en medios de cultivo selectivo Agar S-S por cada muestra. Diez placas se dejaron incubar a $37^{\circ} \mathrm{C}$ por $24-36$ horas.

Pasado el tiempo de incubación, identificarón colonias con características que podrían ser salmonella, de esta maneras se seleccionaron estas colonias y cepario en
Agar nutritivo para formar el incubado a $37^{\circ} \mathrm{C}$ por 24 horas.

Una vez listo los ceparios con las colonias repotenciadas, con ayuda de un asa de siembra en punta, se tomó una pequeña muestra de cada tubo y se procedió a sembrar por el método de picadura en el medio SIM y se dejó incubar a temperatura ambiente por 24 horas para observar los resultados.

Para el medio TSI, LIA y CITRATO DE SIMMONS, se procedió también a la siembra por picadura profunda y estria en superficie en los dos primeros, y en el Citrato solo por estriamiento en superficie. Se dejo incubar a $37^{\circ} \mathrm{C}$ durante 24 horas. (Figura 3)

\section{RESULTADOS}

En el primer análisis microbiologico de esta investigación se encontró en un $100 \%$ la presencia de bacteria Gram negativas fermentadoras de citrato en las muestras analizadas (A, B, C, D y E); identificando al género Citrobacter, y dentro de ellos las especies Citrobacter amalonaticus y/o Citrobacter diversus (Tabla 1.) 


\section{Realización de las pruebas bioquímicas}

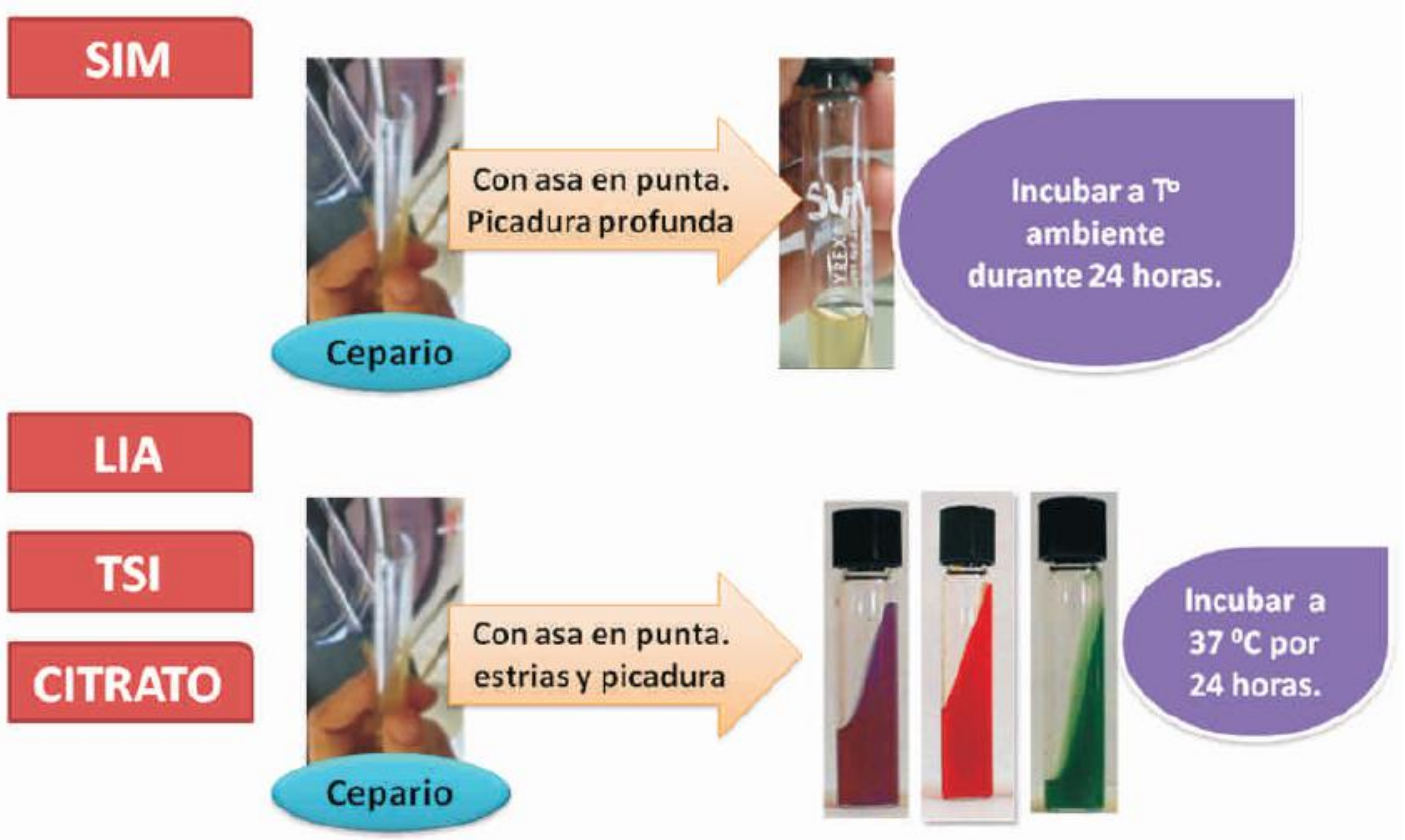

Fig. 3. Realización de las pruebas bioquímicas

Tabla 1.- Pruebas Bioquímicas realizadas para determinar las bacterias presentes las 5 muestras.

\begin{tabular}{|c|c|c|c|c|c|c|}
\hline \multicolumn{2}{|c|}{ Pruebas bioquímicas } & $\mathbf{A}$ & B & C & D & $\mathbf{E}$ \\
\hline & CITRATO & + & + & + & $\mathbf{v}$ & + \\
\hline & LIA & $\mathbf{k} / \mathbf{k}$ & $\mathbf{k} / \mathbf{k}$ & $\mathbf{k} / \mathbf{k}$ & $\mathbf{k} / \mathbf{k}$ & $\mathbf{k} / \mathbf{k}$ \\
\hline & TSI & + & + & + & + & + \\
\hline \multirow{3}{*}{ SIM } & MOTILIDAD & + & + & + & + & + \\
\hline & INDOL & + & + & + & + & + \\
\hline & $\mathbf{H}_{2} \mathrm{~S}$ & + & - & - & - & - \\
\hline \multirow{2}{*}{\multicolumn{2}{|c|}{$\mathrm{CO}_{2}$}} & - & - & - & - & + \\
\hline & & \multicolumn{5}{|c|}{ Citrobacter diversus } \\
\hline
\end{tabular}

- En el segundo análisis microbiologico, se encontró la presencia de bacteria Gram negativas fermentadoras de citrato, en un $20 \%$ de las muestras la que correspondía a la Facultad de Ciencias Económicas y Empresariales; obteniendo
5 colonias que presentaban las caractersirticas representativas, identificando a Citrobacter amalonaticus, Citrobacter diversus, y Citrobacter freundi (Tabla 2) 
Tabla 2.- Pruebas Bioquímicas realizadas para determinar las bacterias presentes en las 5 muestras.

\begin{tabular}{|c|c|c|c|c|c|c|}
\hline \multicolumn{2}{|c|}{ Pruebas bioquímicas } & $\mathbf{A}$ & B & $\mathrm{C}$ & D & $\mathbf{E}$ \\
\hline & CITRATO & + & + & + & + & + \\
\hline & LIA & $\mathrm{k} / \mathrm{k}$ & $\mathrm{k} / \mathrm{k}$ & $\mathrm{k} / \mathrm{k}$ & $\mathrm{k} / \mathrm{k}$ & $\mathrm{k} / \mathrm{k}$ \\
\hline & TSI & + & + & + & + & + \\
\hline \multirow{3}{*}{ SIM } & MOTILIDAD & + & + & + & + & + \\
\hline & INDOL & - & + & + & - & + \\
\hline & $\mathrm{H}_{2} \mathrm{~S}$ & + & - & + & + & + \\
\hline \multirow{2}{*}{\multicolumn{2}{|c|}{$\mathrm{CO}_{2}$}} & - & - & - & - & - \\
\hline & & $\begin{array}{l}\text { Citrobacter } \\
\text { freundi }\end{array}$ & \multicolumn{2}{|c|}{ Citrobacter diversus } & $\begin{array}{l}\text { Citrobacter } \\
\text { freundi }\end{array}$ & \begin{tabular}{|c|} 
Citrobacter \\
amalonaticus. \\
y/o diversus
\end{tabular} \\
\hline
\end{tabular}

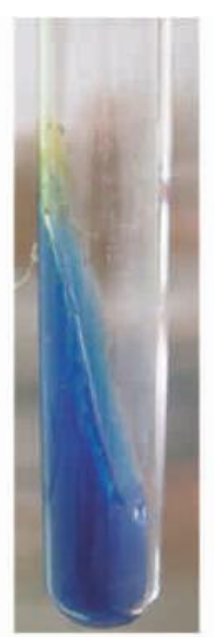

CITRATO

$+$

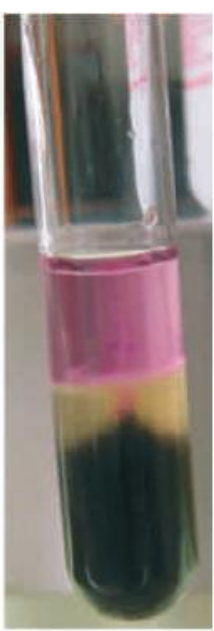

SIM

INDOL + MOTILIDAD +

$\mathrm{H} 2 \mathrm{~S}+$

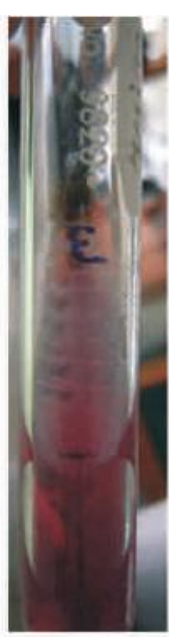

LIA

$\mathrm{k} / \mathrm{k}$

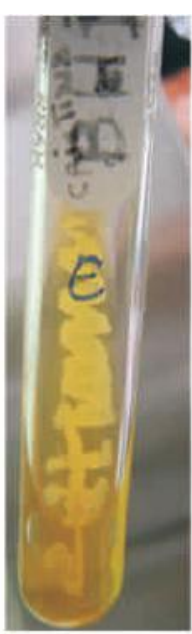

TSI

$+$

\section{CONCLUSIONES}

- La presencia del género Citrobacter, en sándwich aunque no se ha relacionado con patologías importantes a nivel gastrointestinal, sirve como un indicador para determinar que la inocuidad del producto en el lugar es inadecuada.

- $\quad$ EL hecho de no haber encontrado Salmonella sp. en los triples estudiados no quiere decir que esta bacteria está ausente, de debería realizar otro análisis con un mayor número de muestra y un mayor tiempo de vigilancia sanitaria para tener la certeza de que los alimentos preparados que ingresan a la universidad reúnen las condiciones de seguridad alimentaria.
- A pesar de la ausencia de Salmonella sp., la presencia del género Citrobacter y la información bibliográfica nos ayuda a inferir que el punto crítico de la preparación de sándwiches triples es la manipulación y las condiciones del ambiente de trabajo desde el inicio (donde se realiza la primera etapa de la elaboración y empaquetado? Una respuesta que solo las autoridades universitarias nos la pueden dar)

- Se debe tener en cuenta las normas sanitarias difundidas por DIGESA para la preparación de los alimentos y así evitar enfermedades gastrointestinales u otros.

- Debería haber un Programa de Vigilancia Sanitaria para determinar la calidad e inocuidad de los 
productos envasados y preparados al interior y los que ingresan de afuera de la institución y verificar la no presencia de organismos patógenos y/o alterenates de los alimentos, como es el caso de la venta de sándwich triple en la universidad Ricardo Palma.

\section{LITERATURA CITADA}

AGURTO, T. 2009. Microbiología Bioquímica Bacteriana Enterobacteriaceae. Primera Edición. Cap. II, 49-51.

BROCK, T. et al. 2003. Brock Biología de los Microorganismos. Decima Edición. Cap.12, 368-371.

MAHON, C. \& Manuselis, G. 2000. Textbook of Diagnostic Microbiology. $2^{\mathrm{Ed}}$. USA. Sauder Editions.

MURRAY, P., Baron, E., Tenover, F. \& Yolken, R. 1999. Manual of Clinical Microbiology. 7 (ed.). ASM Press. Washington DC.

SERVICIO DE INOCUIDAD e Inspección de los Alimentos Departamento de Agricultura de los Estados Unidos. 2006. Salmonella: Preguntas y respuestas. Estados Unidos.
SANZO, M., Sanzo, J. 1994. Salmonela.

VANDERZANT，C. \& Splittstoesser, D. 1995. Compendium of methods for the microbiological examination of foods. APHA. Washington DC.

MICHANIE, S., Benvenaste, S. 1996. Salmonellosis por consume de Sándwiches con huevo duro. Revista DIAETAN 76:47-51. 1996. Buenos aires, Argentina.

PÉREZ-SILVA, M., Belmonte, S., Martínez, J. 1998. Estudio microbiológico de los alimentos elaborados en comedores colectivos de alto riesgo. Rev. Esp. Salud Pública 1998. 77, 67-75.

BOLLING, B.; Schmidt, D. y Ingham, S. 2002. Development of a simple method for detecting presumptive Escherichia coli en fresh retail beef. Journal of Food Science. V67 (1) 2002.

BUSTOS, J; Hamdan, A; Gutiérrez, M. 2006. Sthapylococcus aureus: la reemergencia de un patógeno en la comunidad. Dpto. de Atención a la Salud, Depto. de Sistemas Biológicos. Universidad Autónoma Metropolitana Xochimilco. México, D.F., México. Rev Biomed 2006; 17:287-305. 